\title{
Ser e Tornar-Se Psicoterapeuta Parte II: Diálogo entre Mudanças Pessoais e Profissionais
}

Being And Becoming A Psychotherapist Part II:
Dialogue Between Personal And Professional Changes

Ser Y Tornarse Psicoterapeuta, Parte II: Diálogos Entre Cambios Personales Y Profesionales

Helena Moura de

Carvalho \& Paula Mena

Matos

Faculdade de

Psicologia e de Ciências

da Educação da

Universidade do Porto,

Portugal.
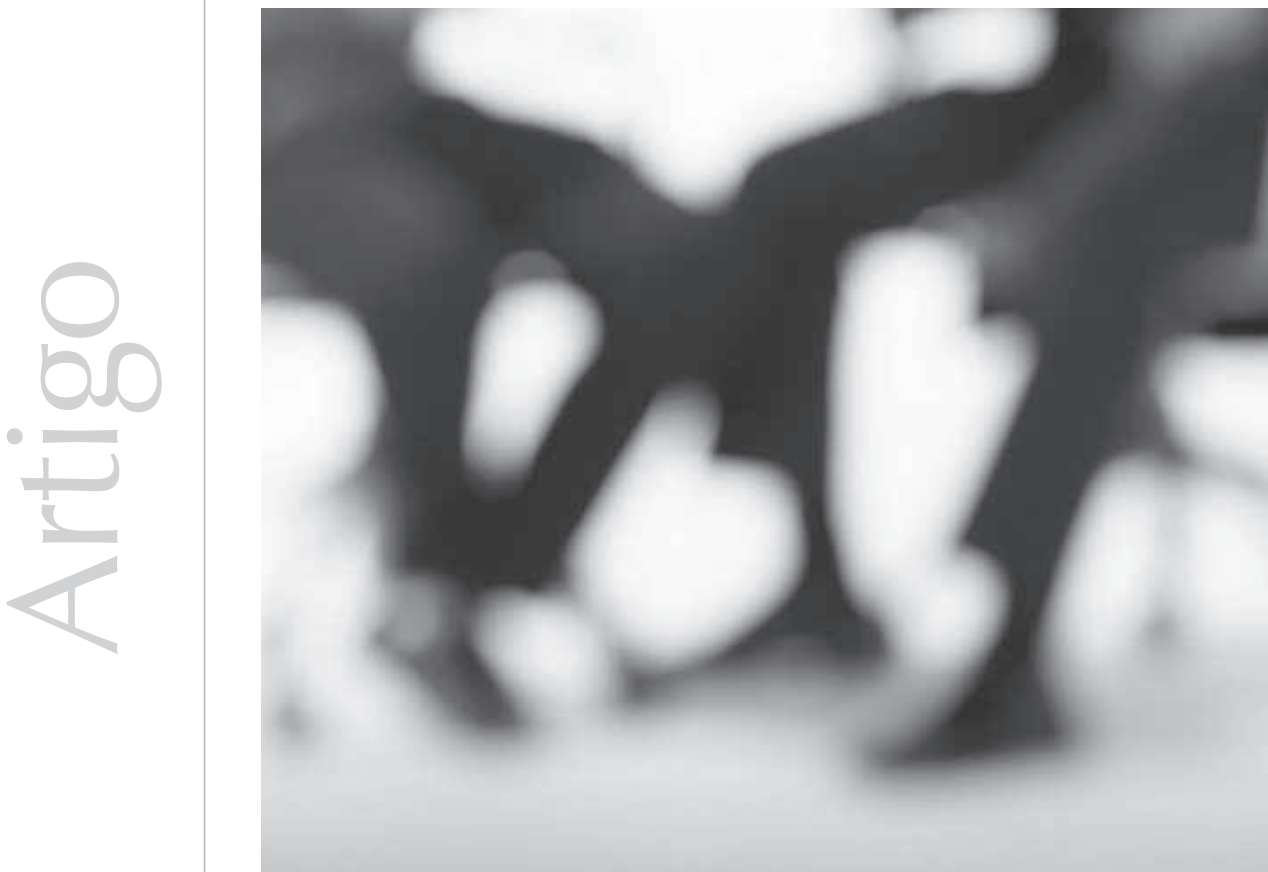
Resumo: Assiste-se, nos últimos anos, na investigação, a um crescente interesse pelo estudo do desenvolvimento profissional do psicoterapeuta. O estudo das características de psicoterapeutas considerados experts representa um importante contributo nesse domínio. O objetivo do presente estudo é analisar as narrativas de 20 psicoterapeutas experts (peritos) de diferentes orientações teóricas (cognitivocomportamental, construtivista, humanista, psicanalítica e sistémica) sobre o seu desenvolvimento pessoal e profissional no decurso da prática clínica. Na análise, emergiram dois grandes temas. No presente artigo, serão apresentados os resultados do segundo tema analisado e as etapas e mudanças do desenvolvimento do psicoterapeuta organizado em dois subtemas, a saber, (a) etapas e mudanças no desenvolvimento do psicoterapeuta no domínio profissional e (b) etapas e mudanças no desenvolvimento do psicoterapeuta no domínio pessoal. Os resultados sublinham a necessidade de se considerar as mudanças ocorridas no domínio pessoal e profissional quando do estudo do desenvolvimento integral do psicoterapeuta.

Palavras-chave: Psicoterapia. Estudo qualitativo. Treinamento pessoal. Desenvolvimento profissional.

Abstract: In recent years we assist in psychotherapy research to a growing interest in studying the professional development of psychotherapists. The study of the characteristics of psychotherapists considered experts is an important contribution to this field. The aim of this study is to analyze the narratives of 20 expert psychotherapists from different theoretical orientations (cognitive-behavioral, constructivist, humanistic, psychoanalytic and systemic) about their personal and professional development along their clinical practice. In the analysis two major themes emerged. In this article we present the results of the second theme examined, the stages of development and changes of the psychotherapist organized in two sub-themes, namely (a) steps and changes in development of psychotherapists working in the professional domain, (b) steps and changes in development of psychotherapists in the personal domain. The findings underline the need to consider the changes in the personal and professional development in the study of the integral development of the psychotherapist.

Keywords: Psychotherapy. Qualitative study. Personnel training. Professional development.

Resumen: Se ve en los últimos años en la investigación un creciente interés en el estudio del desarrollo profesional del psicoterapeuta. El estudio de las características de psicoterapeutas considerados especialistas representa una importante contribución en este dominio. El objetivo del presente estudio es analizar las narrativas de 20 psicoterapeutas especialistas (peritos) de diferentes orientaciones básicas (cognitivocomportamental, constructivista, humanista, psicoanalista y sistémica) sobre su desarrollo personal y profesional en el curso de la práctica clínica. En el análisis han emergido dos grandes temas. En el presente artículo serán presentados los resultados del segundo tema analizado, etapas y cambios del desarrollo del psicoterapeuta organizado en 2 subtemas. Son ellos: (a) etapas y cambios en el desarrollo del psicoterapeuta en el dominio profesional; y (b) etapas y cambios en el desarrollo del psicoterapeuta en el dominio personal. Los resultados remarcan la necesidad de considerarse los cambios ocurridos en el dominio personal y profesional del estudio del desarrollo integral de la personal del psicoterapeuta.

Palabras-clave: Psicoterapia. Estudio cualitativo. Desarrollo personal. Desarrollo profesional.

Assiste-se, nos últimos anos, a um crescente interesse pelo estudo do desenvolvimento profissional do psicoterapeuta (Neufeldt, 1999). Esse interesse emerge em diferentes domínios da investigação, tais como o desenvolvimento da carreira, o processo de supervisão e o desenvolvimento psicológico na idade adulta (Rønnestad \& Skovholt, 2003). O estudo do desenvolvimento do psicoterapeuta assume especial relevo com dados mais recentes que sublinham que as características dos psicoterapeutas parecem ser mais determinantes nos resultados psicoterapêuticos do que os métodos e as técnicas aplicadas (para uma revisão, ver meta-análise de Wampold, 2001).
A necessidade de realizar estudos transteóricos que contribuam para uma compreensão do desenvolvimento do psicoterapeuta através do estudo de psicoterapeutas experts já havia sido detectada em meados do séc. XX por Fiedler (1950). No artigo emblemático The concept of an ideal therapeutic relationship, o autor apresenta resultados comparativos entre psicoterapeutas de três escolas teóricas no que respeita à definição da relação psicoterapêutica ideal. A principal conclusão do seu estudo privilegia a componente experiencial, visto que psicoterapeutas experts de diferentes orientações concordam mais entre si do que não experts da mesma orientação no que concerne à conceptualização da relação psicoterapêutica. 
Apesar de decorridos 60 anos desde 0 artigo de Fiedler, o estudo do desenvolvimento dos psicoterapeutas e das características que definem os experts em psicoterapia é um desafio ainda atual (Skovholt, Hanson, Jennings, \& Grier, 2004).
Apesar de decorridos 60 anos desde o artigo de Fiedler, o estudo do desenvolvimento dos psicoterapeutas e das características que definem os experts em psicoterapia é um desafio ainda atual (Skovholt, Hanson, Jennings, \& Grier, 2004). Esse desafio emerge de duas principais questões de investigação. A primeira associa-se com a definição de eficácia em psicoterapia e com a posterior identificação de psicoterapeutas experts. Em um domínio tão complexo e ambíguo como a psicoterapia, cujo percurso se define por avanços e recuos, sendo por isso errático e não linear, torna-se difícil operacionalizar critérios que definam inequivocamente o conceito de expertise e de desenvolvimento do psicoterapeuta. As teorias existentes do desenvolvimento do psicoterapeuta focamse sobretudo no estudo de fases iniciais, sendo que pouco tem sido realizado na investigação no sentido de operacionalizar conceitos subjacentes ao desenvolvimento do psicoterapeuta (Orlisnky \& Rønnestad, 2005). Um critério amplamente utilizado no sentido de proceder à diferenciação de psicoterapeutas experts e não experts baseava-se nos anos de experiência, na formação e na supervisão. Alguns estudos encontraram uma relação significativa entre anos de experiência e resultados, no entanto, a magnitude de efeito dessa relação era baixa (Crits-Cristoph \& Mintz, 1991; Stein \& Lambert, 1995); outros não encontraram mesmo qualquer relação (Dawes, 1994). A inconsistência da investigação poderá ser explicada pelas limitações metodológicas subjacentes aos estudos supracitados. Hillerbrand e Claiborn (1990) afirmam que o fato de se tratar de desenhos metodológicos fora do contexto real de consulta impossibilita a análise do componente relacional da interação entre psicoterapeuta e cliente, componente que parece estar relacionado com a definição de expertise em psicoterapia (Luborsky, McLellan, Woody, O'Brien, \& Auerbach, 1985; Teyber \& McClure, 2000). Outra questão prende-se ao desafio inerente ao cliente e à problemática em consulta. Skovholt, Rønnestad e Jennings (1997) dizem que são os clientes com histórias relacionais mais difíceis e que posteriormente revelam maior dificuldade no estabelecimento de laços relacionais com o psicoterapeuta que parecem diferenciar a eficácia de um psicoterapeuta expert e não expert. No entanto, e dadas as questões éticas subjacentes à investigação em psicoterapia, nomeadamente no contexto real de consulta, psicoterapeutas não experts têm menos acesso a casos considerados mais difíceis, o que dificulta a sua comparação (Skovholt et al., 1997). Em suma, o estudo do desenvolvimento dos psicoterapeutas e da assumpção de expertise em psicoterapia parece estar pontuada de inconsistências várias dada uma multiplicidade de factores que emergem sobretudo com a natureza dialética do fenómeno em análise e dos agentes envolvidos, psicoterapeuta, cliente e a relação psicoterapêutica.

A segunda questão associa-se ao desenho metodológico do estudo do desenvolvimento do psicoterapeuta. Para podermos compreender o impacto da experiência no seu desenvolvimento, seria necessário avaliar os resultados e o seu posicionamento processual em diferentes parâmetros da prática psicoterapêutica. A fim de cumprirmos esse objetivo, o desejável seria utilizar um desenho metodológico longitudinal (Rønnestad \& Skovholt, 2003). No entanto, esse desenho apresenta algumas desvantagens, nomeadamente, a morosidade no processo de recolha de dados. Tal como sustentamm Orlinsky e Rønnestad, o desenvolvimento profissional do psicoterapeuta pode prolongarse por quatro ou mais décadas, sendo, portanto, inviável, em um estudo com limitações temporais restritas, utilizar uma metodologia longitudinal. A morosidade no processo de recolha acarreta também gastos financeiros adicionais e maior mortalidade da amostra. 
Uma outra abordagem metodológica no estudo desenvolvimento do psicoterapeuta consiste em uma comparação transversal feita em diferentes etapas de desenvolvimento profissional. No entanto, apesar do desenho metodológico transversal suprir as limitações de desenhos longitudinais, poderão surgir dificuldades na identificação das diferenças que são atribuídas a mudanças que refletem genuinamente o desenvolvimento do psicoterapeuta e a mudanças atribuídas a variáveis sociohistóricas no domínio da psicoterapia (Orlinsky \& Rønnestad, 2005).

No sentido de resolver as limitações das opções metodológicas supracitadas, os autores propõem a utilização de uma abordagem fenomenológica, que consiste em perguntar aos psicoterapeutas as representações acerca do próprio desenvolvimento desde o início da carreira até ao presente. Essa abordagem é particularmente interessante quando o próprio fenómeno a ser investigado não está claramente definido e operacionalizado (Orlisnky \& Rønnestad, 2005). A limitação subjacente a essa abordagem é o enviesamento subjetivo emergente da construção de significados atribuídos ao percurso desenvolvimental e a desejabilidade social pelos psicoterapeutas, nomeadamente em estudos que não impliquem o anonimato entre investigador e participante.

No presente estudo, optámos pela utilização de uma abordagem fenomenológica, com o objetivo de analisar as narrativas de 20 psicoterapeutas experts (peritos) de diferentes orientações teóricas (cognitivocomportamental, construtivista, humanista, psicanalítico e sistémica) sobre o seu desenvolvimento pessoal e profissional no decurso da prática clínica. O recurso a essa abordagem e a uma metodologia qualitativa associa-se ao carácter exploratório da investigação, visto que não pretendemos desenhar trajetórias desenvolvimentais, mas contribuir para a operacionalização do desenvolvimento dos psicoterapeutas a partir da emergência de conceitos que ultrapassam o domínio profissional. Dadas as limitações de espaço de publicação e a especificidade da análise qualitativa em causa, este é o segundo artigo de apresentação dos resultados do estudo. No primeiro artigo (Carvalho \& Matos, 2011), foram apresentados os resultados relativos às experiências relacionais do desenvolvimento do psicoterapeuta, sendo que neste segundo serão abordadas as representações das etapas e das mudanças do seu desenvolvimento.

\section{Método}

\section{Participantes}

Para a identificação da amostra de psicoterapeutas experts em Portugal, utilizamos a técnica da nomeação por pares (peer nomination). Essa técnica é descrita por Jennings e Skovholt (1999) pela sua capacidade de precisão para avaliar as características pessoais e interpessoais dos psicoterapeutas e em outros grupos de sujeitos. Segundo Luborsky et al. (1985), os psicoterapeutas parecem saber discriminar entre os colegas potencialmente mais eficazes do ponto de vista psicoterapêutico e os menos eficazes. Através da nomeação por pares, nove psicoterapeutas de diferentes orientações identificaram colegas que são por si percepcionados como "bons psicoterapeutas" e aos quais recorreriam em caso de terapia pessoal. Foram selecionados 23 psicoterapeutas de diferentes orientações teóricas e instituições acolhedoras que reuniam maior consenso na nomeação.

Dos 23 psicoterapeutas contactados, 20 aceitaram participar do estudo. As idades variam entre 35 e 77 anos $(M=50,35$ anos; $D P=9,95)$, e os anos de experiência, entre os 10 e os 44 ( $M=21,4$ anos; $D P=8,79)$. Relativamente à distribuição por sexo, 11 dos entrevistados são do 
sexo feminino, e 9, do sexo masculino. Relativamente ao background profissional, 16 dos psicoterapeutas entrevistados são psicólogos, 3 psiquiatras e 1 médico de clínica geral. Quanto às orientações teóricas, 4 identificam-se predominantemente com o modelo cognitivo-comportamental (cc), 5, com o modelo construtivista (c), 3, com o humanista (h), 4, com o psicanalítico (p) e 4, com o sistémico (s).

\section{Instrumento e procedimento}

No presente estudo, optou-se por utilizar uma metodologia qualitativa de investigação. Elaborou-se uma entrevista semiestruturada para o efeito, com 16 perguntas de resposta aberta, agrupadas em 7 temas centrais do processo desenvolvimental dos psicoterapeutas (Carvalho \& Matos, 2006), a referir:

1) motivações subjacentes à escolha de Psicologia/ psiquiatria;

2) motivações para ser psicoterapeuta;

3) desenvolvimento como psicoterapeuta (principais mudanças, agentes de mudança, estilo pessoal e características que permaneceram estáveis);

4) concetualização atual do processo de mudança terapêutica e das principais características do psicoterapeuta que melhor contribuem para o processo terapêutico e para a promoção de mudança em psicoterapia;

5) impacto de ser psicoterapeuta na vida pessoal e relacional;

6) atuais dificuldades na prática;

7) aspirações futuras relativamente ao desenvolvimento como psicoterapeuta.

As entrevistas foram realizadas pela investigadora nos contextos de trabalho dos psicoterapeutas (à exceção de duas entrevistas) entre outubro de 2006 e março de 2007, e tiveram uma duração média de 50 minutos. No início da entrevista, era explicado o objetivo geral do estudo e era pedida a anuência dos participantes para proceder à gravação da entrevista em formato audio. Seguidamente, procedeu-se à transcrição in verbatim das entrevistas, tendo em conta a natureza discursiva e prosódica das respectivas narrativas.

\section{Estratégia de análise dos dados}

A análise dos dados foi realizada através da grounded theory (Glaser \& Strauss, 1967; Strauss \& Corbin, 1990), que se define como metodologia de pesquisa fundamentada nos dados, cuja construção de conhecimento emerge de uma perspetiva cíclica e comparativa, ou seja, não estão definidos a priori os conteúdos a analisar, nem existe uma grelha teórica definida que possa delinear a análise das unidades de sentido a relevar na investigação. Sendo assim, uma característica central dessa metodologia assenta-se em uma preocupação por um conhecimento que emerge dos dados e que é, portanto, não apriorístico ou verificativo. O processo de análise é simultaneamente dedutivo e indutivo (Charmaz, 2000; Strauss \& Corbin, 1990).

Na análise, emergiram 2 grandes temas: (a) experiências relacionais que contribuíram para o desenvolvimento dos psicoterapeutas e (b) etapas e mudanças do desenvolvimento do psicoterapeuta. Dadas as limitações de espaço de publicação e a natureza da análise, no presente artigo, serão apresentados os resultados do segundo tema organizado em dois subtemas, a saber: (a) etapas e mudanças no desenvolvimento do psicoterapeuta no domínio profissional e (b) etapas e mudanças no desenvolvimento do psicoterapeuta no domínio pessoal (vide Fig. 1). O tema organizador ou história core identificado remete para o desenvolvimento do psicoterapeuta: diálogo e coerência entre self pessoal e profissional que, sendo transversal na análise preconizada, representa uma leitura síntese integrada dos dois subtemas 
supracitados do desenvolvimento do psicoterapeuta. Para uma compreensão da história core organizadora dos temas supracitados, vide Carvalho e Matos (2011).

\section{Resultados ${ }^{1}$}

Tema

\section{Etapas e mudanças}

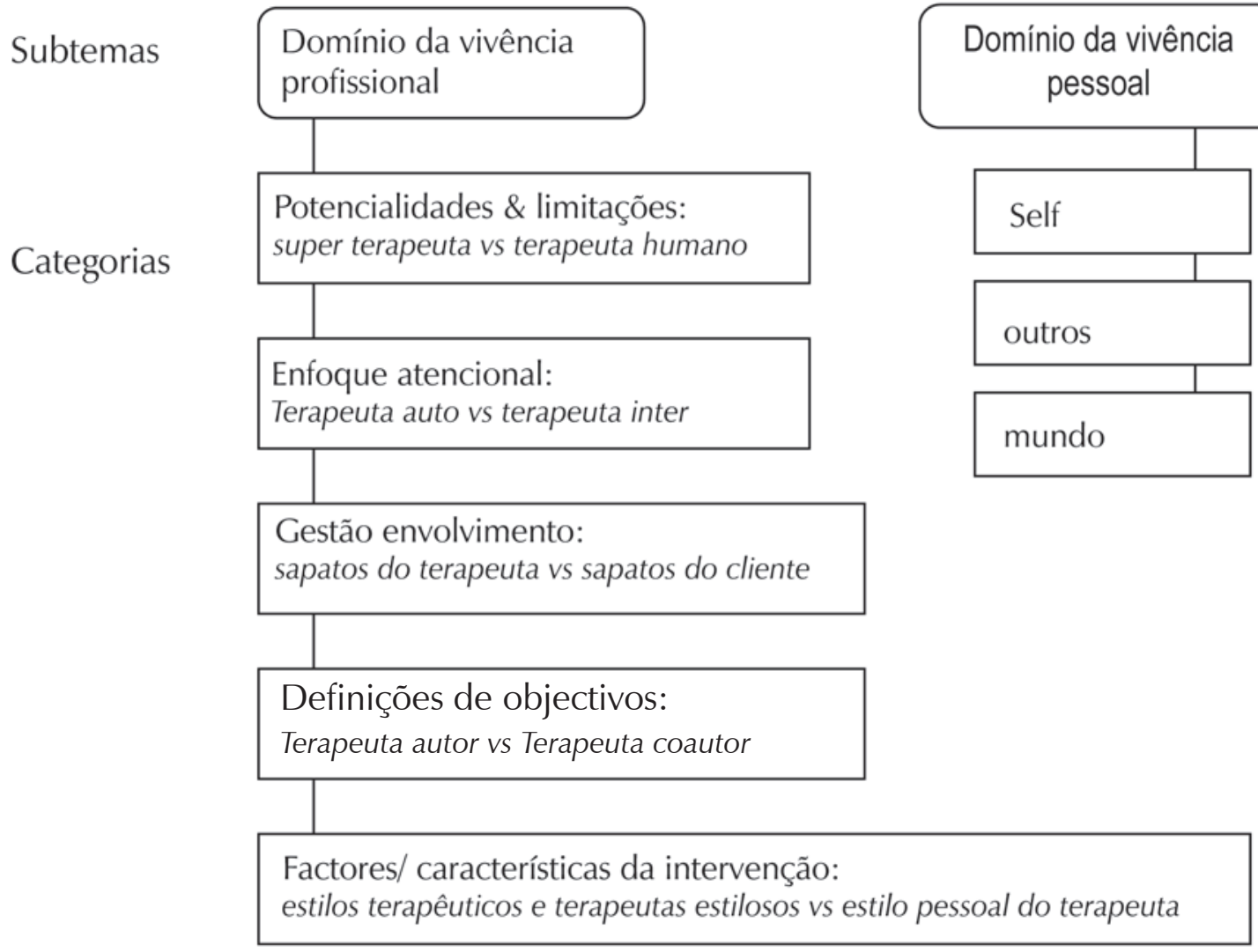

1 No sentido de auxiliar o leitor na identificação e compreensão das narrativas transcritas,

Figura 1. Organização do tema etapas e mudanças do desenvolvimento do psicoterapeuta, subtemas, categorias e sub-categorias 


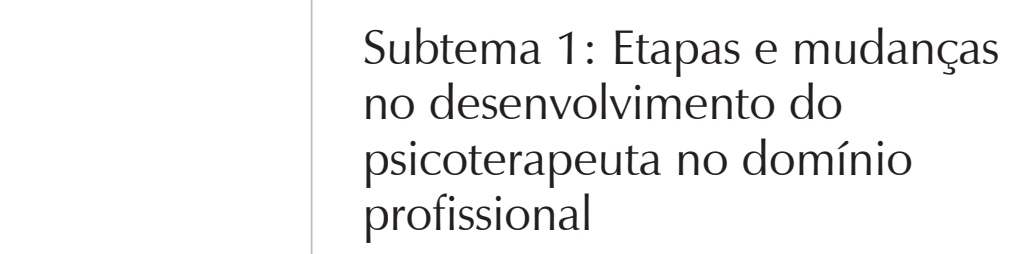

teórica (cc-cognitivo comportamental, c-construtivista, h-humanismo, p-psicanalista, s-sistémica), a segunda é relativa ao número de entrevista dentro do mesmo modelo, e a terceira, relativa ao sexo do entrevistado (m-masculino e f-feminino). Por exemplo: (p1m) p corresponde a orientação psicanalista, 1 ao número do psicoterapeuta dentro da orientação psicanalítica e m corresponde ao sexo masculino.
Os psicoterapeutas entrevistados relataram que, no decurso do seu desenvolvimento, construíram diferentes representações acerca da psicoterapia e do seu papel como psicoterapeutas. Essas mudanças são percecionadas como contrastantes e significativas, contraste esse presente na expressão citada por dois dos entrevistados: "é o dia e a noite" (p1m, cc2m). As representações das principais mudanças abordadas pelos clientes na definição da psicoterapia e do seu papel como psicoterapeutas foram organizadas em cinco categorias, a saber:

1.1. Potencialidades e limitações da psicoterapia e do psicoterapeuta: super psicoterapeuta vs psicoterapeuta humano;

1.2 Enfoque atencional na avaliação do desempenho do psicoterapeuta: psicoterapeuta auto vs psicoterapeuta inter;

1.3 Gestão do envolvimento e da proximidade emocional: sapatos do cliente vs sapatos do psicoterapeuta;

1.4 Papel do psicoterapeuta e do cliente na definição dos objetivos da terapia: psicoterapeuta autor vs psicoterapeuta coautor;

1.5 Fatores subjacentes à intervenção do psicoterapeuta (enfoque externo e interno): estilos psicoterapêuticos e psicoterapeutas estilosos vs estilo pessoal do psicoterapeuta.

Cada categoria é definida por domínios bipolares de análise que conferem um movimento de mudança subjacente às representações de desenvolvimento do psicoterapeuta. Esses domínios não implicam, no entanto, um estado/fase de desenvolvimento estático e exclusivo, mas são representados pelos psicoterapeutas como trajetos desenvolvimentais de um percurso errático e de diálogo constante das estruturas pessoais e profissionais do seu self. São, assim, categorias dialéticas de procura de coerência entre os desafios promovidos pela prática e as estruturas e o sentido de identidade do psicoterapeuta. Esses domínios apresentamse como referências espontâneas na narrativa do sujeito perante o questionamento da sua mudança como psicoterapeuta e na visão da psicoterapia. Passemos ao desenvolvimento de cada uma das categorias, recorrendo a transcrições das narrativas dos entrevistados.

1.1. Potencialidades e limitações da psicoterapia e do psicoterapeuta: super psicoterapeuta vs psicoterapeuta humano

As potencialidades e limitações da psicoterapia e do psicoterapeuta são, no início da prática clínica, representadas por uma fantasia idealizada (p1m), de omnipotência ingénua (c1m) e de salvação (c1m) do outro, representações essas explicitadas nas seguintes afirmações:

- É como uma ilusão muito, muito forte que vamos mudar o mundo, ou que vamos mudar as pessoas, que temos um armamentário fabuloso, ou que temos armas nucleares fabulosas para mudar as pessoas. (c2m)- Há muito o mito da psicoterapia e do que é que é isso de ser psicoterapeuta, como se fosse assim uma pessoa (...) que tem assim uma magia qualquer, assim uma coroa iluminada à volta da cabeça que os distingue dos outros! (c3f)

Essas representações iniciais emergem no contexto quer de expectativas internas do psicoterapeuta acerca do seu papel na ajuda psicoterapêutica, quer de expectativas externas e socio-culturais do exercício da psicoterapia. O psicoterapeuta incorpora o 
- Hoje em dia tenho muito mais segurança, porque também não me sinto pressionada a resolver os problemas do mundo, e acho que o problema da juventude é que nós achamos que podemos ajudar as pessoas e que tudo se vai resolver e que temos que ajudar mesmo. E, portanto, não temos esse peso na cabeça. (cc1f). que chamamos o super psicoterapeuta, e a sua prática clínica é mistificada em termos de possibilidade de ajuda e de promoção de mudança nos clientes. Essas expectativas são promotoras de estados de ansiedade elevados e de maior insegurança face à não apresentação de resultados imediatos heteroimpostos pelo psicoterapeuta. No decurso da prática clínica, a progressiva perceção da natureza limitada da ajuda psicoterapêutica, a construção do que designamos ser o psicoterapeuta humano é apreendida pela complexidade crescente das possibilidades do espaço psicoterapêutico e do papel do psicoterapeuta no processo. Vejamos como dois psicoterapeutas se referem a essa mudança:

- No início, tinha uma visão um pouco mais idealizada, um pouco mais omnipotente (...) achar que uma psicoterapia poderia resolver os males de uma pessoa e, neste momento, não acho nada disso (...) A psicoterapia é como um fermento nos bolos, se não estão lá os ovos, se não está a farinha, se não estão lá os ingredientes, por mais que se ponha lá o fermento, o bolo não fica como poderia ficar no caso de estarem lá os ingredientes, e essa limitação da realidade, isso eu acho que passei a aceitar, a aceitar e a integrar e a ter a certeza de que o contributo que eu posso dar é limitado. (p3f).

- Hoje em dia tenho muito mais segurança, porque também não me sinto pressionada a resolver os problemas do mundo, e acho que o problema da juventude é que nós achamos que podemos ajudar as pessoas e que tudo se vai resolver e que temos que ajudar mesmo. E, portanto, não temos esse peso na cabeça. (cc1f).

De uma definição mágica da psicoterapia, de um poder sobre-humano do psicoterapeuta e da angústia subjacente a ilusões de salvação, passamos progressivamente para o domínio das possibilidades e das limitações da psicoterapia e da humanização do psicoterapeuta em providenciar ajuda. A compreensão dos limites processuais da psicoterapia passam: (i) pela aceitação de que algumas problemáticas não se inscrevem apenas no domínio psicológico de intervenção e que os clientes poderão beneficiar de um encaminhamento para outros profissionais ou mesmo para outros psicoterapeutas; (ii) pela compreensão do sofrimento como inevitável na vivência e existência humana, e (iii) pela aceitação da ambiguidade/incerteza do processo psicoterapêutico. A compreensão dos limites surge bem expressa nas seguintes afirmações de um psicoterapeuta:

- Aceito melhor o sofrimento na vida das pessoas e na minha própria vida. As vidas são sofridas, não há volta a dar a isso, as vidas têm sofrimento, não somos nós que vamos retirá-lo. Ele continuará a existir, haja psicoterapeutas ou não haja. (c1m)

- Eu sou menos apressado do que era há dez anos também (...) Acho que lidava menos com a ambiguidade; a terapia envolve a gente lidar muito com a ambiguidade, não perceber o que é que temos pela frente, não conseguir fazer sentido do caso e conseguir lidar com esta ambiguidade. (c1m).

A humanização do psicoterapeuta passa assim pelo conhecimento e pela aceitação dos limites profissionais e pessoais em providenciar ajuda psicoterapêutica, sendo o conhecimento e a aceitação desses mesmos limites entendido como importante indicador da sua competência, ilustrado na seguinte afirmação:

- Características fundamentais de um psicoterapeuta? Humildade relativamente ao próprio saber e relativamente à capacidade de poder ajudar o outro a criar mudança. (s3f).

1.2 Enfoque atencional na avaliação do desempenho do psicoterapeuta: 
psicoterapeuta auto vs psicoterapeuta inter Na continuidade de uma perceção de poder ilimitado na ajuda psicoterapêutica no início da prática, caracterizado pelo super psicoterapeuta, surge o que designamos psicoterapeuta auto, visto o psicoterapeuta estar centrado nas suas capacidades e competências para a promoção de ajuda na psicoterapia. O psicoterapeuta auto é caracterizado por uma autocentração no seu desempenho e os pelos ganhos e retrocessos do processo primeiramente atribuídos ao seu desempenho. Vejamos nas afirmações seguintes esse enfoque atencional:

- No início, eu estava tão assustada e tinha tanto receio de não ser capaz de fazer bem as coisas, estava tão preocupada com o que dizia, com o que fazia, com o que pensava, com o que sentia, que basicamente estava ali com um olho gigante sobre mim própria que não me deixava assim tão disponível para os outros. (p3f).

- No início, está-se muito preocupado em não cometer erros, com um medo terrível de dizer uma coisa que transforme terrivelmente a pessoa, que é um exagero completo e absoluto, de que parece que vamos cometer uma coisa que vai levar a pessoa imediatamente ao suicídio. (cc3m).

Essa autocentração é sentida como promotora de estados elevados de ansiedade, angústia, medo e mesmo de sofrimento, compreendida pelos participantes pelo receio de cometer erros que tenham implicações iatrogénicas e que sejam inibidores de uma compreensão holística e relacional do processo psicoterapêutico.

- Eu vivia a terapia com uma intensa ansiedade, ou seja, para mim, aquilo era altamente desconfortável (...). Houve ali uma altura em que eu considerei deixar de fazer, eu pensei porque de facto eu sofria muito com a terapia. Imagine, eu tinha um dia de terapia, eu no dia anterior começava a ficar tenso. (c1m).
A progressiva inclusão de variáveis na definição de eficácia do processo psicoterapêutico como não dependente exclusivamente do desempenho do psicoterapeuta e dos modelos subjacentes à sua intervenção e a um entendimento relacional do mesmo são promotores de uma progressiva descentração do enfoque atencional do psicoterapeuta para a interação dialógica da psicoterapia que designamos de psicoterapeuta inter.

A prática psicoterapêutica acumulada e refletida devolve um sentido de maior tranquilidade e de segurança na gestão de erros ou impasses psicoterapêuticos, nomeadamente através de perceções de autoeficácia em processos sentidos como desafiantes. A progressiva descentração do psicoterapeuta auto para o psicoterapeuta inter amplia o espaço de consulta, complexifica a psicoterapia e permite ao psicoterapeuta a descoberta do cliente e da sua importância na evolução do processo psicoterapêutico. O psicoterapeuta inter tem assim mais espaço para se permitir experimentar e arriscar psicoterapeuticamente, visto ter uma leitura mais ampla e relacional das suas intervenções. Os clientes passam a ser importantes agentes de aprendizagem, e a relação psicoterapêutica um importante indicador do processo psicoterapêutico. O psicoterapeuta inter passa a estar mais disponível para o outro e para a complexa esfera das relações psicoterapêuticas.

- Eu de facto tinha muito medo de não estar à altura que acabava por não estar disponível para a relação, estava mais preocupada comigo do que com a pessoa e com a relação, e acho que isso felizmente passou! (...) Acho que agora consigo tirar prazer da situação, coisa que na altura não conseguia pelo medo. (p3f).

1.3 Gestão do envolvimento e proximidade emocional: sapatos do cliente vs sapatos do psicoterapeuta 
Um dos fatores que os psicoterapeutas consensualmente indicaram como mais determinante no sucesso psicoterapêutico éa empatia, que, como qualidade incontornável da relação psicoterapêutica, é também caracterizada como um processo difícil e complexo, dado o encontro entre duas realidades epistémicas, a do cliente e a do psicoterapeuta, a gestão da sobrecarga emocional que a vivência vicariante do sofrimento potencia no psicoterapeuta e a dificuldade em estabelecer uma relação genuína de apoio incondicional.

- Será que eu sou verdadeiramente capaz de compreender esta pessoa? Acho que é das coisas mais difíceis de fazer (...) a compreensão, a empatia. Não há muitos encontros com o outro que sejam genuinamente de abertura, com uma disponibilidade total para os outros, isso acontece poucas vezes (...) Estar incondicionalmente ao lado das pessoas não é uma coisa tão fácil assim, nós estamos habituados a acreditar muito condicionalmente. (cc3m).

A polarização desta categoria: sapatos do cliente e sapatos do psicoterapeuta emerge da definição de empatia como metáfora da capacidade do psicoterapeuta se colocar nos sapatos do cliente sabendo que os sapatos não são seus (Rogers, 1957; Skovholt \& Rønnestad, 1995).

Na iniciação da prática psicoterapêutica e no seguimento das categorias anteriormente abordadas, os psicoterapeutas relatam como mais difícil distanciarem-se da vivência de situações psicoterapêuticas. O colocarse nos sapatos do cliente como exercício empático sem o "como se" (Rogers, 1957) poderá acarretar identificação e projeção da vivência do cliente, algo que é definido como problemático, quer no impacto que possa ter na vida do psicoterapeuta e na contaminação de contextos pessoais de interação, quer na qualidade da ajuda prestada aos clientes.
- É um perigo que se corre de a pessoa se deixar absorver de tal maneira, que confunda o mundo à sua volta. (cc3m).

O "absorver de emotividade negativa" (c2m), o "peso das histórias" (c4f), "dormir com os casos" (c3f) são afirmações que nos remetem para o risco da sobreidentificação, ou seja, para o calçar permanente dos sapatos do cliente, e que poderão contaminar outros contextos de interação da vivência pessoal dos psicoterapeutas.

- Passei muitas noites sem dormir a pensar nos casos. E se tinha feito bem, e o que é que eu podia fazer a seguir, e a pensar 'será que vai aparecer, ou não vai aparecer', e 'será que eu disse isto certo ou não disse? E casos que são extremamente angustiantes e que uma pessoa às vezes não está preparada para eles! (...) E nós somos novinhos quando acabamos o curso, não temos traquejo, (s2f).

- Outra coisa importante que se adquire com a experiência é a distância emocional. Eu lembro-me nas primeiras consultas que fazia, ficava com a cabeça cheia. Parecia que levava o peso das histórias das pessoas comigo para casa. (c4f).

O movimento que permite ao psicoterapeuta adotar o quadro de referência do cliente e observar o mundo na sua perspetiva exige a aprendizagem de um distanciamento emocional considerado necessário à ajuda psicoterapêutica. O fechar a porta, o descalçar dos sapatos do cliente protege o psicoterapeuta do desgaste emocional inibidor da relação de ajuda, e parece ser uma conquista importante na obtenção de segurança e tranquilidade no papel como psicoterapeuta, tal como expresso na seguinte afirmação:

- Parece que isso é uma conquista, não ficar aflito com, não ficar ansioso com a ansiedade dos nossos pacientes, nem ficar deprimido 
com as depressões, mas ficar mesmo assim sintónico (...) Ter empatia com a pessoa que nos procura, sem nos deixar invadir. (p2f).

A perceção da individualidade das realidades do cliente e do psicoterapeuta parece ser uma condição sine qua non para a sensibilidade que a compreensão do mundo do outro nos exige:

- Desde cedo também aprendi que não posso levar as coisas para casa, e isso faz com que a pessoa tenha que estabelecer limites (...), e é a única maneira que eu tenho de continuar a emocionar-me e a comoverme com as situações, mas sem que isso me deixe deprimida e nem transporte isso para o resto da minha vida (...), para conseguirmos continuar a estar lá a cem por cento, temos que nos proteger de alguma forma. (cc1f).

1.4 Papel do psicoterapeuta e do cliente na definição dos objetivos da terapia: psicoterapeuta autor vs psicoterapeuta coautor

Tal como fundamentado nas categorias anteriores, no início, as potencialidades da prática psicoterapêutica e do papel do psicoterapeuta são consideradas desajustadas porque exacerbadas (super psicoterapeuta), sendo a eficácia psicoterapêutica definida exclusivamente pelas competências técnicas do psicoterapeuta (psicoterapeuta auto). No decurso desse poder, muitas vezes interpretado como gerador de ansiedade, a definição dos objetivos da terapia é imposta pelos psicoterapeutas, paradoxalmente, em uma perspetiva de expertise. Dizemos paradoxalmente, visto que é precisamente no início da prática, portanto, com menos experiência, que os psicoterapeutas parecem sentir mais necessidade de conduzir a terapia e de ter certezas na intervenção e nos resultados a alcançar, apesar de, como diz um profissional, se tratarem de representações frágeis e enganosas:
- Quando entrava na primeira sessão, eu tinha logo todas as respostas (...) Acho que a omnipotência se traduz muito nisso também de a gente, na primeira sessão, querer perceber tudo, 'agora vou perceber tudo, pronto', 'já sei o que é que vou fazer da próxima vez', e não sabe. (c1m).

Assim, a procura pela objetividade e segurança de uma prática psicoterapêutica validada ainda por expectativas pessoais e socioculturais do poder ilimitado do psicoterapeuta está subjacente na emergência do que designamos ser o psicoterapeuta autor, que se caracteriza por uma definição uníssona dos objetivos da terapia, nomeadamente: (i) pela preocupação na rapidez da identificação do problema/diagnóstico, (ii) pela necessidade de observar mudanças rápidas e de ver as coisas funcionarem, (iii) pela diretividade e imposição ao conduzir o processo psicoterapêutico e (iv) pela estruturação e programação da prática, isto é, pelo recurso à manualização ou a guiões de intervenção:

- No início, era mais um bocadinho, uma coisa rígida, aprende-se de uma determinada forma, conduz-se a primeira entrevista, procurando seguir aqueles passos todos, a pessoa está muito ligada a um guião; no início, é por uma questão de segurança, ter mais segurança (...) Depois, a pessoa esquece-as, mas integra-as de tal maneira que elas parecem que surgem naturalmente, já não se consegue pensar, 'vou pensar agora aqui numa estratégia paradoxal!' (s4f).

O poder do psicoterapeuta autor e a dissonância entre as suas expectativas e a prática psicoterapêutica poderá ser promotora de frustração, desânimo e insegurança. A partilha relacional desse poder se dá em um contexto de alargamento do espaço de consulta com a introdução do cliente e das suas contingências no processo. Vejamos como uma psicoterapeuta representa esse processo de mudança: 
- (no início) Talvez me envolvesse mais no desejo de curar, travasse menos o meu desejo de dirigir um pouco as situações, e tenha aprendido a ficar mais silenciosa, mais capaz de aceitar que a pessoa tem que fazer mais um trabalho interno, mais lento, portanto, uma maior tolerância (...) Os jovens muitas vezes ou ficam ansiosos, porque não conseguem resultados, ou se empenham tanto que parece que querem ser eles os autores da melhoria do nosso paciente, que afinal tem que aprender ele próprio a gerir os seus conflitos, a entender o que é que se passa com ele. (p2f).

Com a ampliação do papel do cliente, surge uma definição colaborativa e partilhada da psicoterapia através do que designamos psicoterapeuta coautor, que se define: (i) pela reinvenção de variáveis como o timing e os contextos alternativos de mudança do cliente e (ii) pelo não controle total e absoluto do percurso psicoterapêutico considerado errático, indefinido e dotado de uma complexidade dialógica, patente na seguinte afirmação:

- Sairmos daquela atitude em que nós é que temos aquele conhecimento que falta à outra pessoa, e entrarmos numa atitude mais de colaboração, de conhecer o outro e de ajudarmos o outro a atingir aquilo que quiser, e não aquilo que eu acho que ele deve atingir; é uma diferença abissal, e dá-nos toda uma forma de estar com a pessoa que é totalmente diferente e que eu acho que é muito mais gratificante, quer para mim neste caso, quer para as próprias pessoas (...) Estar aberto ao outro, à experiência fenomenológica que a outra pessoa traz. (cc1f).

E ainda (iii) pela abertura epistémica e pela humildade psicoterapêutica na definição de competência do psicoterapeuta, tão bem expressas nas seguintes afirmações:

- No momento em que eu me assumo como uma escolha, estou a fazer um péssimo serviço às pessoas; nós temos que dar a responsabilidade às pessoas para elas escolherem. (cc3m)

- Houve uma outra coisa, que já foi mais tardia, que foi eu começar a tomar consciência de coisas que os próprios clientes me ensinavam, que eu acho que no início não tinha muito ... nem sei se deixava que eles me ensinassem. (s3f).

O psicoterapeuta coautor distribui assim o poder na terapia e passa a considerar o cliente como agente incontornável na definição de sucesso psicoterapêutico.

1.5 Fatores subjacentes à intervenção do psicoterapeuta: estilos psicoterapêuticos e psicoterapeutas estilosos vs estilo pessoal do psicoterapeuta

Ao longo da sua formação, o psicoterapeuta tem acesso a formas de pensar sobre a psicoterapia veiculadas quer através de modelos teóricos, quer através de psicoterapeutas seniores e formadores, que possuem quadros de leitura acerca da realidade e do ser humano com referenciais próprios de intervenção.

A incorporação desses quadros, representados pelos psicoterapeutas no início da prática clínica como dotados de uma clareza concetual, abstrata e teorizável, é passível, em um primeiro momento, de suscitar deslumbramento, e pode conferir um sentido de segurança aparente perante o caos inicial fomentado pela complexidade da intervenção psicoterapêutica.

- Digamos que acreditei no modelo de uma forma muito naif, durante três, quatro anos. Foi bom, deu aquela fantasia, aquela segurança um bocadinho inocente dos primeiros anos, convencido que sabia fazer de tudo, que tinha soluções para tudo, portanto, ajudou nesse sentido, deu-me uma certa determinação nas consultas que ajudava. (c2m). 
- Acho que há uma fase de um certo deslumbramento inicial com o modelo, com a teoria, com as possibilidades, ver as pessoas mais seniores falarem-nos do seu trabalho, depois a tomada de consciência de que isto não é tão fácil como parece (...), que estar com um cliente é uma coisa difícil, que requer muito treino, requer uma reflexão pessoal sobre a forma como se está, as dificuldades sentidas (...) Há uma tomada de consciência sobre um caminho pessoal que tem que ser feito. (h2m).

Os fatores norteadores da intervenção, no início da prática psicoterapêutica, são inicialmente inspirados no: (i) recurso a modelosteóricos e práticas manualizadas, dada sua estruturação (estilos psicoterapêuticos) e na (ii) mimetização de psicoterapeutas seniores e no questionamento perante impasses ou dificuldades psicoterapêuticas (psicoterapeutas estilosos). A perceção da prática e do setting psicoterapêutico é progressivamente sentida como rígida e desconfortável, formatada e "com a sensação de se estar a fazer o papel" (cc3m), dada precisamente a adoção de referenciais externos na definição de autenticidade. A apreensão progressiva da (i) não linearização do processo psicoterapêutico e da (ii) diversificação dos modelos, quer teóricos quer em termos de formadores, e a identificação de técnicas, modelos e estratégias de intervenção mais consonantes com o self pessoal do psicoterapeuta possibilitam um estar em terapia mais espontâneo, flexível e individualizado.

O estilo pessoal do psicoterapeuta parece resultar, assim, da síntese e da integração de influências teóricas e dos estilos pessoais dos psicoterapeutas observados e de maior permeabilização e utilização das características pessoais na prática psicoterapêutica, tais como o recurso ao humor, as metáforas e a self-disclosure.
- Estava doutrinado com self control e ausência total de abertura da parte do psicoterapeuta, a ausência total de transferência e as contratransferências e os processos na salinha, e doutrinado com o manual que é 'tu tens que ser o manual, e não tu próprio'. A grande diferença do princípio para cá é que eu estou muito mais à vontade em ser eu próprio e dizer o que sinto e o que penso, como um fator importante na relação psicoterapêutica e para a mudança, portanto a favor do paciente, não a favor do meu bemestar. (c2m).

- É uma etapa importante do percurso como psicoterapeuta, é a pessoa, depois de ler tanta coisa, de ver pessoas trabalhar, de ouvir os seus professores, de trabalhar com eles, de ter um supervisor, de ter um psicoterapeuta, conseguir fazer uma síntese de tudo isso, e dizer assim 'Isto não me interessa, eu não consigo ser assim, eu não quero ser assim, aquilo que me faz sentido e que me faz sentir eu próprio e bem comigo próprio como psicoterapeuta é isto e isto e isto, e clarificar isso dentro de nós, e saber como é que eu estou nas situações de relação psicoterapêutica. (h2m).

A genuinidade e a autenticidade surgem como corolário da integração e da procura de congruência das experiências pessoais e profissionais do psicoterapeuta e inspiram a criatividade subjacente à ajuda psicoterapêutica e a satisfação do desafio que a permanente tentativa de compreensão do outro exige. Vejamos as descrições dos seguintes psicoterapeutas:

- É engraçado (...) estava-me a lembrar duma expressão que o Figo usou, que, se calhar, é parecido com o que eu sinto neste momento (...) (quando the) perguntaram se ele ia jogar aquele jogo com raiva ou com medo e ele respondeu duma forma que eu acho que é 
muito engraçada: 'não, vou jogar sempre como jogo, por gozo'(...) É assim que eu jogo, é assim que eu gosto de jogar e vou jogando assim, e dá-me prazer de fato fazer psicoterapia hoje! É curioso que é uma mudança radical em relação há seis ou sete anos atrás, dá-me gozo, às vezes até me esqueço de mim! (...) Eu gostaria de me poder ver agora há dez anos atrás, porque...UAU!!! (c1m).

- Por outro lado, ao pretendermos que alguém se encontre consigo mesmo e se desprenda dos embrulhos interiores que o limitam, ou seja, que a sua identidade venha ao de cima, teremos igualmente de estar como somos, apesar da técnica. Fingimentos, hipocrisias, palmadinhas nas costas não colam nessa relação $(\mathrm{p} 4 \mathrm{~m})$.

Finalmente, o psicoterapeuta tem espaço para se reinventar e para "estar lá a 100\%" (cc1f), ser capaz de estar com o seu cliente de uma forma verdadeira, "sem máscaras, sem artificialismos e (...) sem defesas, " receios " $(\mathrm{h} 2 \mathrm{~m})$ "

\section{Subtema 2: Etapas e mudanças no desenvolvimento do psicoterapeuta no domínio pessoal}

Para os psicoterapeutas, a natureza da mudança não se verifica apenas no domínio profissional mas também no domínio pessoal, nas suas representações do self, do outro e do mundo, porque, tal como nos diz uma psicoterapeuta, "levo muito do que sou e do que vou aprendendo na minha vida e depois levo necessariamente para a minha vida também do que se passa naquele mundo por isso em dialética muito em harmonia". (c5f)

O presente subtema está organizado em três categorias que representam precisamente as implicações que a prática psicoterapêutica assume nas:
2.1 Representações do self

2.2 Representações do outro

2.3 Representações do mundo

\subsection{Representações do self}

As viagens que a psicoterapia traz para o mundo dos outros, consubstanciadas no processo de empatia presente ao longo do encontro psicoterapêutico, parecem promover o desenvolvimento de um sentido de tolerância, de compreensão "menos superficial e mais profunda" (h1m) do ser humano, que se reflete no self através do autoconhecimento de características pessoais do psicoterapeuta e da aceitação das mesmas. Vejamos como um profissional descreve o impacto de ser psicoterapeuta na sua vida pessoal:

- Do ponto de vista pessoal, eu sinto que a terapia me ajudou muito a crescer e a estar na vida de uma forma mais tranquila, mais serena, menos inquieta, menos angustiada. Aqui está uma questão que eu acho que é muito importante, a ter consciência do meu próprio mundo interior, dos meus próprios receios, das minhas angústias, das minhas inquietações, a não fugir disso, a assumir isso como realmente meu e problemático. (h2m).

É interessante verificar que é precisamente esse um indicador central da ajuda psicoterapêutica, a compreensão e a aceitação, por parte do cliente, de si mesmo. Apesar do papel do cliente ser claramente diferenciado do psicoterapeuta, a dialéctica relacional da psicoterapia parece constituir momento preferencial para um profundo conhecimento do self em relação, tal como afirma uma psicoterapeuta:

- Nós estamos a fazer um processo psicoterapêutico aos nossos clientes e nós estamos a fazer uma psicoterapia a nós próprios. (s2f). 
A vivência vicariante do sofrimento e do limite do humano tem também implicações na relativização de prioridades e na desvalorização daquilo que alguns psicoterapeutas definiram como problemas "triviais" (s2f, cc3m). A reflexão da sua vivência em perspetiva com as vivências de alguns clientes é, de alguma forma, passível de induzir um sentido de privilégio e de alívio e de uma valorização de relações significativas para o psicoterapeuta, como a família e os amigos.

- Perceber aquela história de vida, os problemas daquela pessoa e sentir-me egoisticamente bem com a família que eu tenho, com a história que eu tenho. (...) Às vezes, nem reconheço aquilo que eu tenho à minha volta, por exemplo. Se quiser, o efeito que pode ter é de autovalorização. (c4f).

\subsection{Representações do outro}

No que diz respeito às representações do outro, as principais mudanças a que o psicoterapeuta se refere são o profundo respeito e a admiração pela idiossincrasia do ser humano, tão bem expresso na seguinte afirmação:

- Julgamos, antes de estudar um bocadinho estas coisas, que basta conhecer alguns determinantes e conseguimos prever o comportamento das pessoas, e não é bem assim! (...) Há sempre este aspecto que faz estarmos perante uma pessoa e vê-la como única e irrepetível, quer dizer, cada ser humano como um ser único e irrepetível, não há mais nenhum igual no mundo, e isso acho que é um desafio, é apaixonante. (s4f).

Essa admiração pelo ser humano tem pelo menos três implicações na vivência pessoal do psicoterapeuta. A primeira refere-se a uma avaliação menos rígida, mais aberta e complexa perante comportamentos dissonantes com a sua vivência pessoal:
- A terapia também acaba de influenciar a nossa forma de estar na vida, valores, filosofias, até aspetos mais existenciais, opções que se fazem, o profundo respeito pelas pessoas, o olhar que se tem perante as pessoas e até a atitude compreensiva relativamente a certos comportamentos, que às vezes são vistos como chocantes, estranhos, bizarros, mas nós conseguimos olhar para eles de uma outra maneira, ter uma tolerância e uma compreensão, talvez seja isso a grande influência da terapia: aceitar a diversidade das pessoas e reconhecer que as pessoas têm direito de fazer escolhas na sua vida e que isso é algo que Ihes diz respeito, e que eu não tenho que ter uma influência ou até muitas vezes uma opinião. (h2m).

A segunda associa-se a uma leitura positiva acerca da capacidade de resiliência, de sobrevivência emocional e de atribuição de sentido a vivências consideradas desestruturantes.

- Eu trabalhei com vítimas de tortura (...) Foi uma experiência de aprendizagem fantástica, (...) porque me deu a dimensão do limite quase do humano, que é uma coisa que me interessa, que me espantou! Como é que as pessoas que nós imaginamos que são totalmente destruídas pelas coisas mais hediondas e mais terríveis e, de fato, o lado da tortura é um lado de uma violência inimaginável, e como é que as pessoas são capazes de sobreviver a isto e de se reestruturarem e de viverem bem, o que é uma coisa notável. (cc3m).

A terceira prende-se ao sentido de esperança e de tolerância face aos outros, na crença na resolução dos problemas:

- Acho que a grande mudança que foi ocorrendo em mim, nas minhas relações pessoais, é na aceitação; eu sou uma pessoa muito tolerante, eu acho que a tolerância, a tolerância face aos outros, aparece como corolário deste processo todo, lento, deste 
caldo lento das relações psicoterapêuticas. (h1m).

No entanto, essa mesma complexidade inerente à compreensão do outro, essa avaliação mais "profunda com as coisas de natureza psicológica" (h1m) é passível de promover angústia e incerteza:

- Eu gosto de sentir que a complexidade com que a gente consegue ver as coisas, por um lado às vezes angustia, mas, por outro lado, há uma sensação de plenitude, de que não se dão interpretações às coisas, banais ou corriqueiras ou superficiais, que se procura perceber a lógica das coisas, do funcionamento das pessoas e a complexidade, que às vezes é angustiante, porque somos impotentes para mudar uma série de coisas, mesmo das pessoas que estão ao nosso lado, mas que, por outro lado, por mais angústia ou mais satisfação que dê, dá a noção de que estamos a ver as coisas com alguma profundidade, não nos estão a passar ao lado. (cc2m).

Foram também feitas referências a aprendizagens veiculadas no domínio profissional que foram sentidas quer como positivas na vivência do psicoterapeuta em termos relacionais, nomeadamente na conjugalidade, no divórcio e no recasamento e na parentalidade, visto contribuírem quer para uma vivência menos dramática e criativa dos desafios emocionais, quer como negativas na disponibilidade emocional para os outros, ou seja, os significativos devido às implicações do desgaste emocional da relação psicoterapêutica:

- Acho que, durante o processo de divórcio, consegui evitar uma série de erros, tenho a certeza absoluta, porque conhecia muito teoricamente sobre o divórcio e acho que consegui fazer um bom trabalho aí. Em termos de recasamento, há muitas questões que surgem e que são inevitáveis, e como eu sei que são inevitáveis, não dramatizo, portanto, qualquer outra pessoa, que não saiba que um determinado conflito é inevitável, pode dramatizar. (s1f).

\subsection{Representações do mundo}

Ser psicoterapeuta tem implicações na forma de perspectivar o mundo. O contacto com a diversidade de mundos promovido no contexto da prática clínica parece ser promotor de um olhar flexível e relativizado do mundo.

- Este acesso à vida das pessoas, que elas permitem naturalmente, é extremamente benéfico (...) dá-me uma variabilidade sobre o mundo muito importante, flexibiliza, porque as pessoas às vezes estão no mesmo sítio, vivem com as mesmas pessoas todo o tempo, estão na mesma idade, tornam-se chatos e cínicos e extremamente maldizentes relativamente às pessoas mais novas. Eu acho que isto é o antídoto natural, quer dizer, eu, de alguma forma, sei que o mundo é diverso e isso é bom, é agradável, é interessante, e preparo-me para esse mundo. (cc3m).

Essa diversidade parece também promover um sentido de aceitação da natureza imperfeita e absurda da existência humana:

- E a vida também tem coisas muito absurdas, tem coisas muito violentas, tem coisas muito terríveis que não têm uma explicação no sentido que acontecem, temos que nos preparar para essas coisas (...), a vida não é nada justa, não é nada produtiva em muitas coisas. (cc3m).

São também feitas referências a preocupações de ordem social que emergem das problemáticas vivenciadas na consulta e que parecem, para alguns psicoterapeutas, constituírem informações importantes do estado do mundo: 
- Até o maior impacto é pensar a sociedade nestes últimos anos, é mais já a pensar 'em que sociedade é que eu vivo que traz estes problemas' (...), 'porque é que as pessoas estão assim', 'o que é que traz esta transformação, o que é que nós estamos a fazer de nós, da sociedade e do mundo na pequena parcela que eu posso contribuir'. (cc1f).

Para outros profissionais, a leitura do mundo inspirada pelo seu modelo teórico parece promover um sentido de compreensão que ultrapassa o espaço de consulta e que se inscreve no domínio mais geral da vivência pessoal do psicoterapeuta, tal como expresso na seguinte afirmação:

- Por intermédio da psicanálise, percebi melhor o que era a civilização em geral e como a mal cumprimos. Percebi também as guerras em que vivemos e a forma como poderíamos melhorar os nossos próprios agrupamentos. Deu-me possibilidades de observação e de leitura que considero muito boas. (p4m).

Discussão dos resultados e implicações do estudo

"In the end, each therapist develops his or her own style

and the 'theoretical orientation' fades into the background.

What remains salient is a unique personality combining artistry and skill"

(Strupp, 1978, p. 317).

O objetivo do presente estudo foi analisar as representações e significações de 20 psicoterapeutas peritos de diferentes orientações teóricas e práticas acerca das principais etapas e mudanças decorrentes do exercício da prática psicoterapêutica no seu desenvolvimento profissional e pessoal. Tal como previamente citado (Carvalho \& Matos, 2011), não procuramos desenhar as trajetórias desenvolvimentais do psicoterapeuta, mas, através do recurso a uma abordagem fenomenológica e transteórica, ampliar a representação das mudanças nos psicoterapeutas inspiradas no decurso da sua prática profissional.

No presente artigo, foram apresentados os resultados do tema etapas e mudanças do desenvolvimento do psicoterapeuta, organizado em dois subtemas: (a) etapas e mudanças no desenvolvimento do psicoterapeuta no domínio profissional e (b) etapas e mudanças no desenvolvimento do psicoterapeuta no domínio pessoal, cujas categorias são passíveis de serem analisadas segundo dois eixos principais (vide Fig. 2), o eixo diacrónico e o sincrónico.

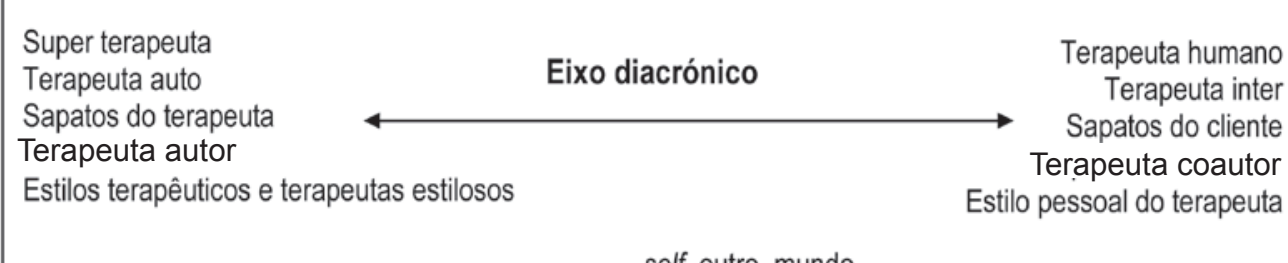

self, outro, mundo

Figura 2. Eixo sincrónico e eixo diacrónico de organização das categorias 
O eixo diacrónico está implícito na bipolarização das categorias e implica a temporalidade das mudanças e os fatores promotores das mesmas. O eixo sincrónico releva a importância de um entendimento integrado e integrador dos domínios analisados, ou seja, as categorias construídas não podem ser entendidas como solavancos desenvolvimentais, mas como focos amplificadores das representações do desenvolvimento do psicoterapeuta.

No eixo diacrónico, podemos inferir um movimento de progressiva diferenciação das representações do psicoterapeuta acerca do seu papel no espaço e no processo psicoterapêutico. Inicialmente, o psicoterapeuta é ampliado nas suas possibilidades de ajuda e surge uma definição centrada nas suas competências técnicas de eficácia psicoterapêutica. Esse enfoque no seu poder passa pela heteroimposição dos objetivos da terapia, dos meios e dos processos subjacentes a uma meta idealizada. A procura pela objetividade e segurança de uma prática psicoterapêutica validada ainda por expectativas pessoais e socioculturais está subjacente à emergência do psicoterapeuta expert. A confrontação com a prática e a integração de experiências desafiadoras da leitura do papel do psicoterapeuta e da psicoterapia se dá em um contexto de alargamento do espaço de consulta, isto é, com a introdução do cliente e das suas contingências no processo. Este representa o promotor central das mudanças no psicoterapeuta. A prática acumulada e refletida e, como diz um dos entrevistados, "O caldo lento das relações psicoterapêuticas" surge como contexto desafiador da complexidade na definição de ajuda psicoterapêutica. As experiências relacionais e o movimento cognitivo e emocional que a compreensão dos clientes exige parecem ser agentes desenvolvimentais na diferenciação das categorias em uma perspetiva temporal. A experiência acumulada só por si não representa um fator diferenciador de psicoterapeutas experts e não experts, mas, tal como afirma Goldberg (1992) no seu livro The Seasoned Psychotherapist: Triumph Over Adversity, a experiência não é garantia de sabedoria, mas constitui excelente oportunidade para a alcançar.

A confrontação com as limitações da psicoterapia e do psicoterapeuta, patentes no movimento inerente à construção de um psicoterapeuta humano, implica a aceitação da incerteza e da ambiguidade, implica que este aceite que o seu exercício profissional não depende apenas e só das suas capacidades técnicas e teóricas. Rønnestad e Skovholt (1991 citado por Skovholt et al., 2004) colocam que um dos erros de psicoterapeutas pouco experientes é precisamente o "encerramento prematuro", isto é, quando face à ambiguidade da prática os psicoterapeutas se agarram a soluções simplistas, teorias ou quadros de referência no sentido de evitarem sentir-se cognitiva e emocionalmente oprimidos. Se, por um lado, essa estratégia poderá ser inibidora de estados de ansiedade e de incerteza profissional, por outro, parece ser essa mesma angústia da ambiguidade um indutor de reflexão e de abertura. Neufeldt, Karno e Nelson (1996) dizem que é precisamente a reflexão a potenciadora de conversão da experiência no expertise.

Uma outra importante característica dos psicoterapeutas do presente estudo associa-se à aprendizagem da gestão do envolvimento emocional. Esses resultados vão no sentido dos resultados do estudo de Rønnestad e Skovholt (2003). Os autores ressaltam que, nas fases iniciais do desenvolvimento dos psicoterapeutas, estes tendem a sobreidentificarem-se com os clientes, e esse sobre-envolvimento pode impedir que seja construída uma relação de ajuda psicoterapêutica. Por outro lado, os autores colocam que aprendizagem da 
gestão emocional é algo bastante difícil, mas crucial para que o psicoterapeuta consiga lidar com o sofrimento humano ao longo do seu percurso profissional. Essa competência desenvolvimental é apelidada de bondaried generosity (Skovholt, Jennings, \& Mullenback, 2004).

Como corolário de aprendizagens veiculadas ao longo da formação do psicoterapeuta, da aprendizagem de técnicas e da mimetização dos seus mestres, surge a progressiva aprendizagem de um estilo pessoal de intervenção. $\mathrm{O}$ autoconhecimento em contexto relacional permite ao psicoterapeuta um estar mais espontâneo, em que o uso de características pessoais parece ser indicador de genuinidade e de transparência na relação psicoterapêutica. Essa parece ser uma competência síntese de encontro entre os domínios pessoal e profissional do psicoterapeuta. Tal como coloca Benjamin (1978, p. 23), "quanto mais nos conhecemos, melhor podemos entender, avaliar e controlar nosso comportamento e melhor compreender e apreciar o comportamento dos outros. Quanto mais familiarizados connosco mesmos, menor a ameaça que sentimos diante do que encontramos".

Não acreditamos que a aprendizagem de técnicas e de modelos não sejam cruciais para uma prática psicoterapêutica eficaz; no entanto, conforme Skovholt, Jennings e Mullenback (2004), o treino de competências técnicas, apesar de constituir uma importante parte do tornar-se um psicoterapeuta expert, não é suficiente. Para Boris (2008), a sobrevalorização da componente teórica na formação dos psicoterapeutas poderá acarretar riscos, que se associam essencialmente ao uso da teoria em psicoterapeutas iniciantes como defesa contra as dúvidas suscitadas no decurso do processo psicoterapêutico e contra a subsequente adoção de uma postura formal, intelectual e perfecionista. Assim, o movimento inerente ao desenvolvimento do psicoterapeuta parece ultrapassar o domínio tecnicista e inscrever-se em uma lógica de desenvolvimento humano e humanizado.

Do ponto de vista sincrónico, as categorias inerentes ao psicoterapeuta humano, ao psicoterapeuta inter, aos sapatos do cliente, ao psicoterapeuta coautor e ao estilo pessoal do psicoterapeuta refletem uma imagem mais limitada do poder do psicoterapeuta, mas uma imagem também mais ampliada das suas potencialidades. O cliente partilha esse poder, e é, precisamente por um lado, a relação que estabelece com o psicoterapeuta o indicador do sucesso psicoterapêutico, e, por outro, a relação que o psicoterapeuta estabelece com o cliente um promotor central do seu desenvolvimento. Como revela Sullivan acerca da sua prática psicoterapêutica (2001 citado por Skovholt et al., 2004), "eu tenho muito conhecimento, muitas competências, mas estas seriam desperdiçadas se a relação não estivesse presente" (p. 97). É interessante também verificar que o autoconhecimento veiculado pela prática psicoterapêutica, a confrontação com a incerteza, a abertura ambiguidade, a adoção do referencial interno do outro expande-se ao domínio pessoal da vivência do psicoterapeuta. Esse segundo subtema, etapas e mudanças no desenvolvimento profissional do psicoterapeuta: implicações no domínio pessoal, é um indicador do desenvolvimento profissional em um quadro mais amplo de desenvolvimento integral do psicoterapeuta. A admiração pela capacidade combativa dos clientes e pela resiliência perante as dramáticas parece potencializar a curiosidade pelo outro e um sentido de tolerância e de compreensão genuína. No mesmo sentido, Rønnestad e Skovholt (2003) identificaram no seu estudo, como um dos temas do desenvolvimento dos psicoterapeutas, a vivência extensiva do sofrimento como promotor do reconhecimento, da aceitação e da apreciação da variabilidade humana. 
Ao longo da análise, quer em uma perspetiva sincrónica, quer diacrónica, podemos verificar que a tónica desenvolvimental assenta sobretudo em uma lógica de aprendizagem inter e intrapessoal, e que a componente de competências técnicas parece ser menos enfatizado. No âmbito da formação dos psicoterapeutas, parece-nos que as implicações mais evidentes deste trabalho se associam à necessidade de promover junto dos jovens psicoterapeutas uma abertura à incerteza e à ambiguidade $\mathrm{e}$ uma postura reflexiva perante as dificuldades e os desafios da prática psicoterapêutica. O encerramento prematuro poderá induzir ao desenvolvimento de psicoterapeutas que, distanciados das potencialidades da relação psicoterapêutica, não só providenciem uma ajuda ineficaz mas também consequências iatrogénicas na vida dos clientes. A formação dos psicoterapeutas deverá não só privilegiar a componente cognitiva mas também a emocional e a relacional do seu desenvolvimento profissional, visto que é precisamente a componente relacional o fator mais determinante do sucesso da psicoterapia (Jennings \& Skovholt, 1999).

O presente estudo sublinha também a necessidade de a formação do psicoterapeuta se processar ao longo da vida, sendo para isso necessária a existência de dispositivos formativos que contemplem quer atualizações teóricas e técnicas, quer o seu desenvolvimento pessoal e a sua supervisão, em uma lógica de desenvolvimento integral do psicoterapeuta. No mesmo sentido, Boris (2008) destaca que "a formação de um psicoterapeuta é contínua e sistemática, persistindo ao longo de sua vida profissional e devendo ser sempre condizente com sua vida pessoal e as diversas opções e experiências que ele faz e vivencia" (p.167).

As limitações do presente estudo estão relacionadas sobretudo com a metodologia utilizada e com o método de recolha da amostra. Pelo fato de tratar-se de um estudo qualitativo do reduzido número da amostra, os dados não poderão ser generalizados para outros psicoterapeutas. Adicionalmente, não poderemos considerar a presente amostra como representativa de psicoterapeutas experts (peritos) em Portugal dado o processo de identificação ter sido realizado através do método de nomeação por pares. Para uma leitura mais extensiva das limitações, vide Carvalho \& Matos, 2011.

Em suma, o presente estudo sublinha a importância de se considerar dimensões da história pessoal e profissional do psicoterapeuta na compreensão do seu desenvolvimento profissional, no sentido de potencializar a compreensão das implicações do seu papel no processo psicoterapêutico como fator incontornável na definição de qualidade e de eficácia psicoterapêutica, e assim promover o desenvolvimento de expertise em psicoterapia. Tal como afirmam Skovholt, Jennings e Mullenback (2004, p.140), "Expertise is not about narrow skill development. It is becoming, over a long time, fully human". 


\section{Helena Moura de Carvalho}

Bolseira de doutoramento pela Fundação para a Ciência e Tecnologia, Faculdade de Psicologia e de Ciências da Educação da Universidade do Porto, Portugal.

E-mail: helena.mrmc@gmail.com

\section{Paula Mena Matos}

Investigadora e Professora Auxiliar da Faculdade de Psicologia e de Ciências da Educação da Universidade do Porto, Portugal.

E-mail: pmmatos@fpce.up.pt

\section{Endereço para envio de correspondência:}

Faculdade de Psicologia e de Ciências da Educação da Universidade do Porto

Rua do Dr. Manuel Pereira da Silva, Porto, Portugal CEP: 4200-392

Recebido 30/6/2010, 1a Reformulação 7/7/2011, Aprovado 12/8/2011. 
Benjamin, A. (1978). A entrevista de ajuda. São Paulo: Martins Fontes.

Boris, G. D. J. B (2008). Versões de sentido: um instrumento fenomenológico-existencial para a supervisão de psicoterapeutas iniciantes. Psicologia Clínica, 20(1), 165-180.

Carvalho, H., \& Matos, P. M. (2006). Entrevista sobre o psicoterapeuta. Manuscrito não publicado.

Carvalho, H., \& Matos, P. M. (2011). Ser e tornar-se psicoterapeuta Parte I: diálogo entre experiências pessoais e profissionais. Psicologia: Ciência e Profissão, 31(1), 80-95.

Charmaz, K. (2000). Grounded theory: Objectivist and constructivist methods. In N. Denzin, \& Y. Lincoln (Eds.) Handbook of qualitative research (2nd., pp. 509-535). Thousand Oaks, CA: Sage.

Crits-Christoph, P. \& Mintz, J. (1991). Implications of therapist effects for the design and analysis of comparative studies of psychotherapies. Journal of Consulting and Clinical Psychology, 59, 20-26.

Dawes, R. (1994). House of cards: Psychology and psychotherapy built on myth. New York: Free Press.

Fiedler, F. E. (1950). A comparison of therapeutic relationships in psychoanalytic, nondirective and adlerian therapy. Journa of Counsulting Psychology, 14, 436-445.

Glaser, B. G., \& Strauss, A. L. (1967). The discovery of grounded theory: Strategies for qualitative research. New York: Aldine.

Goldberg, C. (1992). The seasoned psychotherapist: Tryumph over adversity. New York: W. W. Norton \& Company.

Hillerbrand, E., \& Claiborn, C. D. (1990). Examining reasoning skill differences between expert and novice counselors. Journal of Couseling and Development, 68, 684-691.

Jennings, L., \& Skovholt, T. M. (1999). The cognitive, emotional, and relational characteristics of master therapists. Journal of Counseling Psychology, 46, 3-11.

Luborsky, L., McLellan, A. T., Woody, G. E., O'Brien, C. P., \& Auerbach, A. (1985). Therapist success and its determinants. Archives of General Psychiatry, 42, 602-611.

Neufeldt, S. (1999). Supervision strategies for the first practicum (2nd ed.). Alexandria, VA: American Counseling Association.

Neufeldt, S. A., Karno, M. P., \& Nelson, M. L. (1996). A qualitative of experts' conceptualization of supervisee reflectivity. Journal of Counseling Psychology, 43, 3-9.

Orlinsky, D. E., \& Rønnestad, M. H. (2005). How psychotherapists develop: A study of therapeutic work and professional growth Washington D.C: APA.
Rønnestad, M. H., \& Skovholt, T. M. (2003). The journey of the counselor and therapist: Research findings and perspectives on development. Journal of Career Development, 30(1), 5-44.

Rogers, C. R. (1957). The necessary and sufficient conditions of therapeutic personality change. Journal of Counsulting Psychology, 21, 95-103.

Skovholt, T. M., Hanson, M., Jennings, L., \& Grier, T. (2004). Expertise in therapy and counseling. In T. M. Skovholt, \& L. Jennings (Ed.), Master therapists: Exploring expertise in therapy and counseling (pp. 1-16). Boston: Allyn \& Bacon.

Skovholt, T. M., Jennings, L., \& Mullenbach, M. (2004). Portrait of the master therapist: Developmental model of the highlyfunctioning self. In T. M. Skovholt, \& L. Jennings (Ed.), Master therapists: Exploring expertise in therapy and counseling (pp. 125-146). Boston: Allyn \& Bacon.

Skovholt, T. M., \& Rønnestad, M. H. (1995). The evolving professional self: Stages and themes in therapist and counselor development. New York: Wiley.

Skovholt, T. M., Rønnestad, M. H., \& Jennings, L. (1997). In search of expertise in counseling, psychotherapy, and professional psychology. Educational Psychology Review, 9, 361-369.

Stein, D. M., \& Lambert, M. L. (1995). Graduate training in psychotherapy: Are therapy outcomes enhanced? Journal of Consulting and Clinical Psychology, 63, 182-196.

Strauss, A., \& Corbin, J. (1990). Basics of qualitative research: Grounded theory procedures and techniques. Newbury Park, CA: Sage Publications.

Strupp, H. (1978). The therapist's theoretical orientation: An overrated variable. Psychotherapy: Theory, Research and Practice, 15(4), 314-317.

Teyber, E., \& McClure, F. (2000). Therapist variables. In C. R. Snyder, \& R. E. Ingram (Eds.), Handbook of psychological change (pp. 62-87). New York: Wiley.

Wampold, B. E. (2001). The great psychotherapy debate: Models, methods, and findings. New Jersey: Lawrence Erlbaum. 